\title{
Utilização de NaCl no Suplemento como Alternativa para Viabilizar o Sistema de Alimentação de Bezerros em Creep-Feeding ${ }^{1}$
}

\section{Alexandre Amstalden Moraes Sampaio, Rodolfo Marques de Brito ${ }^{3}$, Geraldo Maria da $\mathrm{Cruz}^{4}$, Maurício Mello de Alencar ${ }^{4}$, Pedro Franklin Barbosa ${ }^{4}$, Rogério Taveira Barbosa ${ }^{4}$}

RESUMO - Foram utilizados 32 bezerros lactentes da raça Canchim, mantidos em sistema de pastejo rotativo de Brachiaria brizantha cv. Marandu, divididos em três grupos correspondentes aos tratamentos avaliados: controle (sem creep-feeding); SAL5 (adição de 5\% de $\mathrm{NaCl}$ ao concentrado fornecido no creep-feeding); e SAL10 (adição de 10\% de $\mathrm{NaCl}$ ao concentrado fornecido no creep-feeding). O arraçoamento em cocho privativo teve duração de 90 dias, divididos em três subperíodos de 30 dias. O ganho de peso corporal foi maior nos subperíodos 1 e 2 para os tratamentos SAL10 e SAL5, respectivamente. Não houve diferenças no terceiro subperíodo e, no período total, o tratamento SAL10 $\left(0,91 \mathrm{~kg} \cdot \mathrm{animal}^{-1} \cdot \mathrm{dia}^{-1}\right)$ foi superior ao tratamento controle $\left(0,81 \mathrm{~kg} \cdot \mathrm{animal}^{-1} \cdot \mathrm{dia}^{-1}\right)$. A rentabilidade proporcionada pelos tratamentos SAL5 e SAL10 em relação ao lote controle foi de $-12,5$ e 6,0\% ao mês, respectivamente. As diferenças de peso corporal à desmama, em relação ao lote controle, para que o creep-feeding proporcionasse rentabilidade líquida de $0 ; 0,6 ; 1,2$; e $6 \%$ ao mês, deveriam ser de 10,$8 ; 11,0 ; 11,2$; e $12,8 \mathrm{~kg}^{\text {animal }}{ }^{-1}$ para o tratamento SAL5 e de 7,6; 7,7; 7,8; e 9,0 kg.animal ${ }^{-1}$ para o tratamento SAL10. Concluiu-se que a limitação do consumo de suplemento no creep-feeding foi necessária para obtenção de viabilidade econômica no uso desta técnica de criação.

Palavras-chave: bezerros, creep-feeding, desempenho

\section{Use of $\mathrm{NaCl}$ in Supplement as an Alternative to Viabilize the Calf Creep-Feeding System}

\begin{abstract}
Thirty two Canchim suckling calves, maintained on rotational grazing system of Brachiaria brizantha cv. Marandu, were divided in three groups corresponding to three evaluated treatments: control (without creep-feeding); SAL5 (addition of $5 \%$ of $\mathrm{NaCl}$ to concentrate fed in creep-feeding); and SAL10 (addition of $10 \%$ of $\mathrm{NaCl}$ to concentrate fed in creep-feeding). Feeding in a creep-feeding system lasted 90 days, divided in three subperiods of 30 days. The body weight gain was greater in the subperiods 1 and 2 for SAL10 and SAL5 treatments, respectively. There were no differences in the third subperiod and, in the overall period, the SAL10 treatment $\left(0.91 \mathrm{~kg}\right.$.animal ${ }^{-1}$.day $\left.{ }^{-1}\right)$ was better than control treatment $\left(0.81 \mathrm{~kg}\right.$.animal ${ }^{-1}$. day $\left.{ }^{-1}\right)$. The monthly remuneration provided by the treatments SAL5 e SAL10 related to the control group were -12.5 and $6.0 \%$, respectively. The body weight differentials at weaning, compared to the control group, for creep-feeding provide a monthly net profit of $0,0.6,1.2$, and $6.0 \%$ should be $10.8,11.0,11.2$, and $12.8 \mathrm{~kg}_{\text {. }}$ nimal $^{-1}$ for SAL5 and 7.6, 7.7, 7.8, and $9.0 \mathrm{~kg}^{\text {. animal }}{ }^{-1}$ for SAL10. It was concluded that the limited supplement intake in creepfeeding was necessary to obtain economic viability.
\end{abstract}

Key Words: calves, creep-feeding, performance

\section{Introdução}

A fase do ciclo produtivo que engloba a criação do bezerro propriamente dita, que freqüentemente dura cerca de 200 dias, é sempre motivo de especial atenção por parte do produtor de gado de corte, pois é nessa fase do sistema de produção que muitos fatores importantes começam a interferir no bom desenvolvimento do bezerro. Se a matriz foi bem alimentada no período de gestação, especialmente no pré-parto, deverá parir um produto saudável e, a partir daí, dar condições para o intenso desenvolvimento do bezerro. No entanto, isso pode não ser tarefa exclusiva da vaca, sendo necessária a intervenção do criador para que o crescimento do bezerro seja contínuo e progressivo. Fornecer boas pastagens, mineralização e suplementação alimentar é fundamental para explorar ao máximo o potencial genético presente em cada indivíduo.

Nesse contexto, a técnica de alimentação suplementar denominada creep-feeding pode assumir grande importância e, conforme as circunstâncias, tornar-se

\footnotetext{
${ }_{1}^{1}$ Projeto Fapesp n 97/06792-1 (Acordo de cooperação técnico-científica Embrapa/CPPSE e Unesp/FCAV)

2 Prof. Adjunto do Depto. de Zootecnia FCAV/Unesp - Via de acesso Prof. Paulo D. Castellane s/n - CEP: 14884-900 - Jaboticabal (SP). Bolsista CNPq. E.mail: sampaio@fcav.unesp.br

${ }^{3}$ Pós-graduando em Zootecnia (Doutorado) FCAV/Unesp. Bolsista Fapesp. E.mail: rmbrito@fcav.unesp.br

${ }^{4}$ Pesquisador Embrapa Pecuária Sudeste (CPPSE). Home-page: http://www.cppse.embrapa.br
} 
quesito indispensável para encurtar o tempo necessário ao acabamento dos animais para abate, além de proporcionar significativo descanso da matriz, o que resulta em melhoria das suas funções reprodutivas, pois alivia a carga produtiva a ela imposta. Por outro lado, a suplementação deve ser criteriosa e adequada às condições de produção de cada sistema, sendo necessária uma avaliação de cada dieta, indicando se há equilíbrio entre os alimentos e se os requerimentos são atendidos, sem gastos desnecessários de nutrientes.

Taylor \& Field (1999) enumeraram como vantagens do creep-feeding: 1) maior peso corporal à desmama; 2) expressão do potencial genético em animais melhorados; 3 ) impulso na comercialização de animais de raças puras; 4) redução do estresse à desmama; 5) descanso à matriz. Por outro lado, os mesmos autores descreveram algumas desvantagens da suplementação para bezerros lactentes: 1) custo do peso corporal adicional pode ser mais alto do que a receita; 2) técnica delicada para aplicação em fêmeas de reposição; 3 ) pouca diferença ao sobreano entre animais que receberam ou não o suplemento; 4) pouca ou nenhuma diferença de preço na comercialização pós-desmama de animais que receberam ou não o suplemento.

Pacola et al. (1977) estudaram o efeito de alimentação suplementar para bezerros em aleitamento sobre o peso à desmama e pós-desmama, quando então as fêmeas ficaram em pastejo até 20 meses e os machos até 15 meses, sendo confinados a seguir por 120 dias. Durante o aleitamento, o lote que recebeu suplemento consumiu $1,15 \mathrm{~kg}$ de suplemento.animal ${ }^{-1} \cdot$ dia $^{-1}$ (ração com $80 \%$ de milho desintegrado com palha e sabugo $+20 \%$ de torta de algodão). Até os quatro meses de idade não houve diferença entre lotes que receberam suplemento e o lote controle, mas aos sete meses, os animais do lote que consumiram suplemento estavam, em média, $27,1 \mathrm{~kg}$. animal ${ }^{-1}$ mais pesado. O mesmo foi observado aos 15 meses, quando os animais que receberam alimento suplementar estavam, em média, 22 kg.animal ${ }^{-1}$ mais pesados do que as testemunhas. Aos 20 meses, a vantagem das fêmeas com alimentação adicional sobre as fêmeas testemunha foi de $17 \mathrm{~kg}$.animal ${ }^{-1}$, e a vantagem dos machos, de 31,6 kg.animal ${ }^{-1}$, após o confinamento de 120 dias. Após o confinamento, $56 \%$ dos machos do creep-feeding alcançaram o peso corporal de $430 \mathrm{~kg}$, o que foi observado em apenas $12 \%$ dos machos do grupo controle.

Em outro trabalho, Pacola et al. (1989) utilizaram
495 bezerros da raça Nelore, nascidos de 1983 a 1986, divididos em dois lotes: creep-feeding x controle (sem creep-feeding). A dieta foi composta de $80 \%$ de milho e $20 \%$ de farelo de algodão, registrando-se consumo médio de $0,328 \mathrm{~kg}$. animal ${ }^{-1} \cdot \mathrm{dia}^{-1}$. Aos quatro e sete meses de idade, houve superioridade do lote que recebeu suplemento em 5,6 e 13 kg.animal ${ }^{-1}$, acompanhada de redução na mortalidade. Os bezerros filhos de primíparas e de vacas velhas foram os que mais se beneficiaram da suplementação e, de modo geral, as vacas com filhos que consumiram suplemento apresentaram maior eficiência reprodutiva e maior ganho de peso durante o aleitamento.

No trabalho que deu continuidade ao anterior, Pacola et al. (1991) avaliaram o efeito da suplementação no desempenho pós-desmama dos animais e registraram perda de peso de $9 \mathrm{~kg}$. animal $^{-1}$ imediatamente após a desmama. Os animais foram confinados e, aos 383 dias de idade, observou-se uma vantagem de 7,4 kg.animal ${ }^{-1}$ para o lote que recebeu suplemento. Após o confinamento, os animais foram levados ao pasto por um período de 167 dias e não se observou diferença entre os animais do grupo controle e aqueles que consumiram suplemento. Concluiu-se que a influência da suplementação sobre os pesos pós-desmama persistiu até a idade de 18 meses, embora tenha diminuído de 13,2 kg. animal ${ }^{-1}$ aos 210 dias para 7,4 kg.animal-1 aos 383 dias.

Nesta mesma linha de investigação, Martin et al. (1981), trabalhando com machos da raça AberdeenAngus, confinados pós-desmama até 365 dias de idade, verificaram que os bezerros com alimentação adicional no aleitamento mantiveram a vantagem observada à desmama com uma diminuição da vantagem em $2 \mathrm{~kg}$. animal ${ }^{-1}$. Curiosamente, no caso das fêmeas que foram alimentadas para ganhos de 0,5 kg.animal ${ }^{-1} \cdot \mathrm{dia}^{-1}$ pós-desmama, os animais de creep-feeding, que apresentavam uma superioridade de $10 \mathrm{~kg}$.animal ${ }^{-1}$ à desmama, foram ultrapassados pelas testemunhas em $7 \mathrm{~kg}^{\mathrm{animal}}{ }^{-1}$ aos 365 dias de idade.

Pacola et al. (1993) avaliaram o efeito da suplementação alimentar nas fases pré- e pós-desmama, em fêmeas zebuínas da raça Nelore, sobre os pesos e ganhos aos 210, 390 e 550 dias de idade, constituindo quatro lotes experimentais: 1) suplementação pré- e pós-desmama; 2) suplementação pré-desmama; 3) suplementação pós-desmama; e 4) sem suplementação. A ração do creep-feeding foi composta de $80 \%$ de milho e $20 \%$ de farelo de algodão, registrando-se um consumo 
médio de $0,328 \mathrm{~kg} \cdot$ animal $^{-1} \cdot \mathrm{dia}^{-1}$. Na fase pós-desmama, os animais receberam diariamente $9,9 \mathrm{~kg}$ de silagem de milho e $0,69 \mathrm{~kg}$ de farelo de algodão. As fêmeas com suplementação pré- e pós-desmama e as fêmeas com suplementação pré-desmama foram superiores às demais aos 210 dias $\left(13,7 \mathrm{~kg}_{\text {. animal }}{ }^{-1}\right)$,

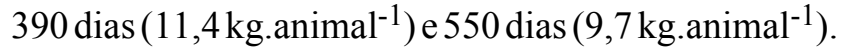
Os animais que receberam suplemento pré- e pósdesmama foram superiores aos que não receberam aos 390 e 550 dias em 45,9 e 23,6 kg.animal ${ }^{-1}$, respectivamente, e os animais que consumiram suplemento após a desmama foram superiores às testemunhas aos 390 e 550 dias de idade em 30,4 e 10,2 kg.animal ${ }^{-1}$, respectivamente.

Lusby (1995) estudou os benefícios de adoção da técnica do creep-feeding sob o complexo ponto de vista das prioridades do bezerro lactente quanto à ingestão de nutrientes e sugeriu que um eficiente programa de suplementação deve adicionar nutrientes à dieta do bezerro e não substituir nutrientes que naturalmente estariam presentes no leite e na forragem ingeridos. Por essa ótica, o autor explicou que a utilização de suplementos com consumo limitado pode tornar o creep-feeding uma técnica economicamente viável, com o objetivo de corrigir deficiências nutricionais e manter elevada a ingestão de forragem pelo animal. O autor avaliou o efeito de suplementação em três lotes: suplemento limitado; suplemento ad libitum; e sem suplemento. Os animais com suplementação à vontade foram os mais pesados à desmama, porém apresentaram conversão alimentar igual a 7,8 adicionada com o suplemento, enquanto que o lote com suplemento limitado apresentou conversão igual a 3,3, indicando que no tratamento ad libitum houve substituição de nutrientes, e não suplementação de nutrientes. O lote com suplemento limitado chegou à desmama 13,6 kg.animal ${ }^{-1}$ mais pesado do que o lote testemunha.

O objetivo deste trabalho foi comparar e avaliar o desempenho de bezerros de corte, em pastagem de capim-marandu, durante a estação chuvosa, recebendo concentrado suplementar à pastagem, visando a limitação da ingestão pela adição de $\mathrm{NaCl}$ ao suplemento.

\section{Material e Métodos}

O trabalho foi conduzido em área de 9 ha de pastejo rotativo de Brachiaria brizantha cv. Marandu, que recebeu aplicação de $130 \mathrm{~kg} \mathrm{~N} \cdot \mathrm{ha}^{-1}$, parcelados em quatro aplicações, na estação chuvosa em que foram criados os bezerros participantes do presente estudo. A área foi dividida em três subáreas experimentais ( 3 ha cada) manejadas num esquema de rodízio com seis dias de ocupação e 42 dias de descanso. Cada subárea de pastejo rotativo foi equipada com um módulo de alimentação seletiva, em ferro galvanizado, instalado na área de descanso dos animais, para viabilizar o arraçoamento diferenciado dos bezerros (creep-feeding), de tal modo que as matrizes ficassem impedidas de alcançar o cocho de alimentação, enquanto os bezerros tiveram livre acesso ao mesmo. Cada módulo de alimentação seletiva, que mediu 5 x $5 \mathrm{~m}$, foi dotado de regulagem lateral nas barras verticais e horizontais e abrigou um cocho com capacidade para alimentação simultânea de 10 animais.

Essa regulagem permitiu um ajuste fino da distância entre as barras verticais, que possibilitou aumento do vão livre à medida que aumentou o tamanho corporal dos bezerros. O módulo de alimentação seletiva foi estrategicamente colocado próximo aos bebedouros, aos cochos de suplementação e mineralização das matrizes.

Foram utilizados 32 bezerros da raça Canchim $(135 \pm 24 \mathrm{~kg})$, divididos em três lotes experimentais, que a partir de 110 dias de idade, começaram a receber uma pequena quantidade de fubádemilho $\left(50 \mathrm{~g} \cdot\right.$ animal $\left.^{-1} \cdot \mathrm{dia}^{-1}\right)$, para que se acostumassem à alimentação dentro do módulo de arraçoamento seletivo. Quando os lotes atingiram em média 120 dias de idade, os animais foram pesados e iniciou-se o fornecimento do suplemento específico para cada tratamento: controle (sem creepfeeding); SAL5 (adição de 5\% de $\mathrm{NaCl}$ ao concentrado fornecido no creep-feeding); e SAL10 (adição de 10\% de $\mathrm{NaCl}$ ao concentrado fornecido no creep-feeding). A idade mais avançada para início de suplementação da pastagem dos bezerros foi indicada por Pacola et al. (1977, 1989, 1991, 1993), em razão da alta relação custo:benefício registrada antes desse período. Dessa forma, o experimento foi estruturado em três subperíodos de 30 dias (com pesagem dos animais ao final/início de cada subperíodo), até a idade de 210 dias (sete meses), quando os lotes foram desmamados, seguindo-se então a pesagem final. Os suplementos foram ajustados de acordo com as recomendações do Sistema de Proteína Digestível no Intestino - PDI (Jarrige, 1990) e compostos por milho em grão, farelo de soja e farelo de algodão, sendo o fornecimento à vontade, realizado diariamente às $10 \mathrm{~h}$. Os ingredientes do concentrado foram 
amostrados diretamente da sacaria, sendo as amostras encaminhadas ao laboratório para serem analisadas. As análises referentes à composição média dos ingredientes, nos teores de matéria seca e proteína bruta, basearam-se nos métodos descritos pela AOAC (1995). A mistura dos ingredientes componentes de cada dieta foi feita em misturador horizontal com capacidade para $500 \mathrm{~kg}$ e dupla rosca helicoidal, durante 12 minutos.

As sobras de alimento do cocho foram quantificadas duas vezes por semana, a fim de estimar a ingestão do concentrado pelos animais. Em razão do período experimental estar inserido no período chuvoso, o recolhimento e a quantificação das sobras também foi realizada nos dias em que houve umedecimento do concentrado como resultado de chuvas de forte intensidade, que não foram contidas pela cobertura do cocho instalada em cada módulo de alimentação seletiva. As fórmulas dos concentrados utilizados no presente estudo estão apresentadas na Tabela 1 .

A formulação da dieta seguiu o balanceamento

Tabela 1 - Proporção dos ingredientes no concentrado (\%) para suplementação da pastagem para bezerros lactentes da raça Canchim de 120 a 210 dias de idade

Table 1 - Proportion of ingredients in concentrate (\%) for pasture supplementation of suckling Canchim calves from 120 to 210 days of age

\begin{tabular}{|c|c|c|}
\hline \multirow[b]{2}{*}{$\begin{array}{l}\text { Ingredientes } \\
\text { Ingredients }\end{array}$} & \multicolumn{2}{|c|}{$\begin{array}{l}\text { Tratamentos } \\
\text { Treatments }\end{array}$} \\
\hline & SAL5 & SAL10 \\
\hline $\begin{array}{l}\text { Milho em grão moído } \\
\text { Grounded corn grain }\end{array}$ & 71,0 & 67,0 \\
\hline $\begin{array}{l}\text { Farelo de soja } \\
\text { Soybean meal }\end{array}$ & 15,0 & 20,0 \\
\hline $\begin{array}{l}\text { Farelo de algodão } \\
\text { Cottonseed meal }\end{array}$ & 9,0 & 3,0 \\
\hline $\mathrm{NaCl}$ & 5,0 & 10,0 \\
\hline $\begin{array}{l}\mathrm{PB}(\%) \\
C P(\%)\end{array}$ & 16,0 & 16,4 \\
\hline $\begin{array}{l}\operatorname{EM}(\mathrm{MJ} / \mathrm{kg})^{2} \\
M E(M J / k g)\end{array}$ & 11,1 & 10,7 \\
\hline $\begin{array}{l}\mathrm{R} \$ / \mathrm{kg} \text { suplemento } \\
R \$ / \mathrm{kg}^{3} \text { supplement }\end{array}$ & 0,196 & 0,197 \\
\hline $\begin{array}{l}{ }^{1} \text { SAL5 (suplemento conte } \\
\text { contendo } 10 \% \text { de NaCl). } \\
2 \text { Estimado por meio de tab } \\
1993 \text { ). } \\
3 \text { US } \$ 1.00=\mathrm{R} \$ 2,00 . \\
{ }^{1} \text { SAL5 (supplement containing } \\
\text { of } \mathrm{NaCl} \text { ). } \\
{ }^{2} \text { Estimated from feed tables co }\end{array}$ & $\begin{array}{l}5 \% \text { de } N \\
\text { de compo } \\
\text { fNaCl); SAL }\end{array}$ & $\begin{array}{l}\text { (suplemento } \\
\text { entos (AFRC, } \\
\text { tcontaining } 10 \%\end{array}$ \\
\hline
\end{tabular}

R. Bras. Zootec., v.31, n.1, p.164-172, 2002 por custo minimizado, sem prescindir das recomendações e dos princípios de alimentação preconizados pelo sistema PDI, considerando a ingestão diária de pastagem de no máximo $2,5 \%$ do peso corporal em matéria seca.

A distribuição dos animais nos tratamentos seguiu o esquema do delineamento inteiramente casualizado, num modelo fatorial $3 \times 3$ (tratamentos $\mathrm{x}$ subperíodos experimentais) com 10, 10 e 12 repetições, para os tratamentos controle, SAL5 e SAL10, respectivamente. As médias de peso corporal inicial e ganho de peso corporal dos tratamentos foram comparadas pelo teste de Tukey (Banzatto \& Kronka, 1992), por meio de contrastes ortogonais no nível de $5 \%$ de probabilidade. Efetuou-se ainda uma análise econômica da adoção da técnica de suplementação da pastagem para bezerros lactentes, considerandose o preço dos ingredientes dos suplementos e o preço de venda dos animais, fornecidos por boletins informativos do setor de pecuária de corte à época da realização do trabalho.

\section{Resultados e Discussão}

Os resultados de consumo do suplemento (desprovidos de análise estatística em razão do arraçoamento em lote) em cada um dos subperíodos experimentais e também a média do período total estão apresentados na Tabela 2. É possível observar que, no $1^{\mathrm{o}}$ subperíodo, o consumo de suplemento pelos bezerros, além de semelhante entre os tratamentos com suplementação, foi também reduzido, situando-se em torno de $0,12 \%$ do peso corporal (180 g.animal $\left.{ }^{-1} \cdot \mathrm{dia}^{-1}\right)$. À medida que os animais se desenvolveram, o consumo aumentou segundo taxas de incremento que variaram entre os tratamentos, notando-se que o aumento de $\mathrm{NaCl}$ na composição do suplemento (tratamento SAL10) resultou em menor consumo relativo $(\% \mathrm{PC})$ de concentrado ao longo de todo o período experimental.

Note-se ainda que no $2^{\circ}$ subperíodo a relação $1: 2$ no teor de sal entre os tratamentos SAL5 e SAL10 praticamente foi refletida de forma inversamente proporcional no consumo do suplemento pelos bezerros. Essa relação estreitou-se bastante no $3^{\circ}$ subperíodo, caindo para 1,5:1, em razão do aumento (3 vezes) no consumo pelos animais do tratamento SAL10, uma vez que o tratamento SAL5 apenas dobrou o consumo em relação do $2^{\circ}$ subperíodo.

Estes resultados sugerem que a ingestão diária de 
Tabela 2 - Ingestão de suplemento $\left(\mathrm{kg}\right.$.animal ${ }^{-1} \cdot \mathrm{dia}^{-1}$ e \%PC.dia $\left.{ }^{-1}\right)$ proporcionado pelos tratamentos avaliados em cada subperíodo e no período total

Table 2 - Supplement intake (kg.animal ${ }^{-1} \cdot$ day $^{-1}$ and $\left.\% B W \cdot d a y^{-1}\right)$ proportioned by evaluated treatments in each subperiod and in overall period Tratamentos 1

Treatments

\begin{tabular}{|c|c|c|c|c|}
\hline \multirow{4}{*}{$\begin{array}{l}\text { Período } \\
\text { Period }\end{array}$} & \multirow{2}{*}{\multicolumn{2}{|c|}{ SAL5 }} & \multirow{2}{*}{\multicolumn{2}{|c|}{ SAL10 }} \\
\hline & & & & \\
\hline & kg.animal ${ }^{-1} \cdot$ dia $^{-1}$ & $\%$ PC.dia ${ }^{-1}$ & kg.animal ${ }^{-1} \cdot$ dia $^{-1}$ & $\%$ PC.dia ${ }^{-1}$ \\
\hline & kg.animal ${ }^{-1} \cdot$ day $^{-1}$ & $\% B W \cdot d a y^{-1}$ & kg.animal ${ }^{-1} \cdot$ day $^{-1}$ & $\% B W \cdot d a y^{-1}$ \\
\hline \multirow{2}{*}{\multicolumn{5}{|c|}{$\begin{array}{l}1^{\mathrm{o}} \text { subperíodo }(1-30 \text { dias }) \\
1^{s t} \text { subperiod }(1-30 \text { days })\end{array}$}} \\
\hline & & & & \\
\hline \multicolumn{5}{|l|}{$2^{\circ}$ subperíodo (31 - 60 dias) } \\
\hline \multicolumn{5}{|l|}{$2^{\text {nd }}$ subperiod ( $31-60$ days $)$} \\
\hline $3^{\circ}$ subperíodo (61 - 90 dias) & 1,37 & 0,69 & 0,92 & 0,43 \\
\hline \multicolumn{5}{|l|}{$3^{\text {rd }}$ subperiod (61-90 days) } \\
\hline Período total (1 - 90 dias) & 0,72 & 0,43 & 0,47 & 0,26 \\
\hline Overall period ( $1-90$ days $)$ & & & & \\
\hline
\end{tabular}

${ }^{1}$ SAL5 (suplemento contendo $5 \%$ de $\mathrm{NaCl}$ ); SAL10 (suplemento contendo $10 \%$ de $\mathrm{NaCl}$ ).

${ }^{1}$ SAL5 (supplement containing $5 \%$ of $\mathrm{NaCl}$ ); SAL 10 (supplement containing $10 \%$ of $\mathrm{NaCl}$ ).

$\mathrm{NaCl}$ pelo animal pode ser dependente de uma série de fatores que interagem entre si, resultando num gradiente de consumo diário que pode não permitir a determinação relativamente precisa da quantidade diária de $\mathrm{NaCl}$ que é ingerida pelo animal. Se isso fosse possível, a ingestão do suplemento poderia ser segura e rigorosamente controlada em função do teor de cloreto de sódio no concentrado suplementar. Há indicações de que à medida que se acentuaram o déficit de produção de leite das vacas e a baixa qualidade da forragem ingerida, no decorrer do período experimental, os animais do lote SAL10 foram impelidos a transcender a quantidade média de consumo diário de $\mathrm{NaCl}$, em vista do aumento em três vezes no consumo de ração.

No período total, o tratamento SAL5 proporcionou maior ingestão absoluta e relativa de concentrado pelos bezerros, com médias de $0,72 \mathrm{~kg}$. animal ${ }^{-1} \cdot \mathrm{dia}^{-1} \mathrm{e}$ $0,43 \%$ PC, respectivamente. Como as quantidades de suplemento consumido no $3^{\circ}$ subperíodo foram as principais determinantes da média geral (em razão do volume de concentrado ingerido), esta média de consumo dos tratamentos avaliados permaneceu na relação próxima de $1,5: 1$, confirmando que a linearidade do teor de sal e do consumo não foi inversamente proporcional.

$\mathrm{Na}$ Tabela 3 encontram-se os resultados do ganho de peso médio dos bezerros, notando-se a superioridade $(\mathrm{P}<0,05)$ dos tratamentos SAL10 e SAL5 nos subperíodos 1 e 2 , respectivamente. No $1^{\circ}$ subperíodo, o tratamento de controle proporcionou ganho de peso semelhante ao tratamento SAL5 e posteriormente assemelhou-se ao tratamento SAL10 no $2^{\circ}$ subperíodo. Já no último subperíodo, os tratamentos não diferiram entre si $(\mathrm{P}>0,05)$. Essa alternância de superioridade dos tratamentos nos subperíodos iniciais do ensaio pareceu estar associada à compensação do crescimento, ou seja, fases de intenso crescimento corporal podem alternar-se com períodos de redução nas taxas de ganho de peso, especialmente em animais que se encontram em nível produtivo acima de 1,5 x manutenção. Nesses casos, as diferenças entre as ondas de crescimento dos tecidos ósseo, muscular e adiposo ficam mais evidentes. Em animais que se desenvolvem em níveis produtivos abaixo de 1,5 x manutenção, há menor distinção entre os períodos de modificação na estrutura, composição e massa corporal.

A média final de ganho de peso corporal de todo o período experimental indicou que os bezerros que receberam o tratamento SAL10 foram superiores aos animais do grupo controle $(\mathrm{P}<0,05)$, embora ambos não tenham diferido do tratamento SAL5.

Este resultado indicou que o efeito de substituição da forragem pelo concentrado suplementar mantevese acentuado no tratamento SAL5, o que impossibilitou a sua diferenciação em relação ao controle. A semelhança observada nas médias de ganho de peso do período total entre o tratamento controle e o tratamento cujo concentrado foi composto com $5 \%$ de sal comum reporta a discussão às considerações tecidas por Lusby (1995). O pesquisador sugeriu que, se os bezerros têm acesso a forragem de qualidade e 
Tabela 3 - Peso corporal inicial e final, conversão do ganho adicional e ganhos de peso corporal (GPC - $\mathrm{kg}^{\mathrm{animal}}{ }^{-1}$.dia $\left.{ }^{-1}\right)$ total e em cada subperíodo e seus respectivos coeficientes de variação (cv)

Table 3 - Initial and final body weight, feed:additional gain ratio and body weight gain (BWG - kg.animal-1.day ${ }^{-1}$ ) total and in each subperiod and respective coefficient of variation (cv)

\begin{tabular}{|c|c|c|c|c|}
\hline \multirow[b]{2}{*}{$\begin{array}{l}\text { Variável }^{2} \\
\text { Variable }\end{array}$} & \multicolumn{4}{|c|}{$\begin{array}{l}\text { Tratamentos }^{1} \\
\text { Treatments }\end{array}$} \\
\hline & Controle & SAL5 & SAL10 & $\operatorname{cv}(\%)$ \\
\hline $\begin{array}{l}\text { Peso corporal inicial (kg.animal } \\
\text { Initial body weight }\left(\mathrm{kg}^{-1} \text { animal }\right. \\
\text { In }\end{array}$ & 134,80 & 128,30 & 141,40 & 17,7 \\
\hline $\begin{array}{l}\text { GPC } 1^{\circ} \text { subperíodo }(1-30 \text { dias }) \\
B W G 1^{\text {st }} \text { subperiod }(1-30 \text { days })\end{array}$ & $0,88^{\mathrm{Ab}}$ & $0,91^{\mathrm{Bb}}$ & $1,10^{\mathrm{Aa}}$ & 13,0 \\
\hline $\begin{array}{l}\text { GPC } 2^{\circ} \text { subperíodo }(31-60 \text { dias }) \\
B W G 2^{\text {nd }} \text { subperiod }(31-60 \text { days })\end{array}$ & $0,91^{\mathrm{Ab}}$ & $1,08^{\mathrm{Aa}}$ & $0,88^{\mathrm{Bb}}$ & 16,1 \\
\hline $\begin{array}{l}\text { GPC } 3^{\circ} \text { subperíodo }(61-90 \text { dias }) \\
B W G 3^{\text {rd }} \text { subperiod }(61-90 \text { days })\end{array}$ & $0,63^{\mathrm{B}}$ & $0,66^{\mathrm{C}}$ & $0,77^{\mathrm{B}}$ & 28,5 \\
\hline $\begin{array}{l}\text { GPC período total ( } 1-90 \text { dias }) \\
B W G \text { overall period ( } 1-90 \text { days })\end{array}$ & $0,81^{\mathrm{b}}$ & $0,89^{\mathrm{ab}}$ & $0,91^{\mathrm{a}}$ & 18,9 \\
\hline $\begin{array}{l}\text { Peso corporal final (kg.animal } \\
\text { Final body weight }\left(\mathrm{kg}_{\text {animal }}^{-1}\right)\end{array}$ & 207,70 & 208,40 & 223,00 & \\
\hline $\begin{array}{l}\text { Peso corporal final (@) } \\
\text { Finalbodyweight }(@)\end{array}$ & 7,20 & 7,22 & 7,73 & \\
\hline $\begin{array}{l}\text { Conversão do GPC adicional } \\
\text { Feed:additional gain ratio }\end{array}$ & - & $9,0: 1$ & $4,7: 1$ & \\
\hline
\end{tabular}

leite materno em quantidades razoáveis, deverão estar ganhando peso próximo do que sua habilidade genética pode lhes permitir. A reduzida efetividade do creepfeeding, com fornecimento de concentrado suplementar à vontade, em aumentar os ganhos dos bezerros nessa condição resulta na substituição da forragem pelo suplemento, tornando a conversão do ganho adicional ruim, pois, em geral, as conversões mais eficientes do creep-feeding ao peso adicional são obtidas quando os bezerros não atingem o seu potencial de crescimento alimentando-se exclusivamente de forragem e leite. No caso do presente estudo, o manejo em pastejo rotativo com adubação intensiva durante as águas pareceu ter propiciado boa forragem, e além disso as matrizes vieram de um longo período de suplementação pré-parto, o que pareceu ter resultado em boa condição corporal e provavelmente em pequena limitação nutricional à produção leiteira na metade inicial da lactação. Mesmo nessa condição, a ingestão apenas de leite e forragem pelos bezerros do tratamento controle indicou que o aporte nutricional permaneceu abaixo do potencial genético dos animais. Nesse caso, era de se esperar que o creep-feeding propiciasse vantagens líquidas em ganho adicional. Todavia, a maior ingestão de concentrado e a ausência de diferenças $(\mathrm{P}>0,05)$ no ganho de peso do tratamento SAL5 em relação ao controle evidenciaram claramente a ocorrência de efeito substitutivo da forragem pelo concentrado. A efetividade da suplementação (e não substituição) da dieta, caso do tratamento SAL10, parece ter proporcionado desempenho compatível com elevada ingestão de forragem, agregada a adequada ingestão de leite e baixa ingestão de suplemento, o que resultou em ganho de peso significativamente maior $(\mathrm{P}<0,05)$ em relação ao tratamento controle. Esse fato pode ainda ser amparado pelas conversões alimentares do ganho de peso corporal adicional observadas para os tratamentos SAL5 e SAL10. Segundo Lusby (1995), as melhores conversões do ganho adicional são obtidas no período invernal e situam-se entre 5 e 9:1. É possível observar que, mesmo no período chuvoso, o tratamento SAL10 permaneceu abaixo do melhor índice citado por aquele autor, com média de 4,7:1.

A análise estatística também revelou diferenças 
entre os subperíodos em cada um dos tratamentos avaliados. A inferioridade $(\mathrm{P}<0,05)$ observada no terço final do ensaio em relação ao início do período experimental pode ser devida à redução do aporte nutricional lácteo e também da disponibilidade (em declínio) de forragem. $\mathrm{O}$ caráter estritamente complementar do concentrado ingerido pelos animais do tratamento SAL10 possibilitou que o ganho de peso no $3^{\circ}$ subperíodo permanecesse semelhante ao do $2^{\circ}$ subperíodo, vantagem não observada nos tratamentos controle e SAL5. Esta diminuição no ganho de peso, no caso do tratamento controle, pode ter sido resultado de um déficit nutricional quantitativo. O efeito substitutivo, evidenciado no tratamento SAL5, explicaria a diminuição no ganho de peso em relação aos períodos iniciais, uma vez que, neste caso, a ingestão de nutrientes oriundos do concentrado foi até maior do que aquela anotada para o tratamento SAL10. No entanto, enquanto este último manteve-se a adicionar nutrientes ao alimento naturalmente disponível aos bezerros, o tratamento SAL5, por meio do efeito de substituição, provocou desequilíbrios dietéticos suficientemente intensos para que se registrasse desempenho semelhante ao do lote que não recebeu suplementação.

Na pecuária de corte brasileira atual, a adoção de qualquer prática de manejo e/ou alimentação deve ser contemplada pela ótica econômica. Ao adotar a técnica do creep-feeding, a questão que freqüentemente se apresenta ao pecuarista é: qual é o custo do ganho adicional. Com efeito, é preciso preocupar-se com esse item, pois um eficiente programa de suplementação de forragem é aquele que resulta num grande aumento do ganho adicional por unidade de suplemento consumido. Muitos criadores e selecionadores de raças puras podem oferecer suplementos arbitrariamente a seus bezerros porque o tamanho e a aparência desses animais são importantes para a comercialização. Já os criadores de animais em escala industrial devem analisar o creepfeeding com base na avaliação de custos e retornos do incremento de peso dos bezerros à desmama.

Constam da Tabela 4 os dados de custo de alimentação de cada tratamento, bem como o diferencial necessário ( $\mathrm{kg}$. animal ${ }^{-1} \mathrm{ou} \% \mathrm{PC}$ ) para que se obtenha viabilidade econômica na adoção de cada ração em relação a um grupo de bezerros que não receberam suplemento, segundo diferentes taxas de rentabilidade pretendidas. As taxas de rentabilidade foram escolhidas por representarem as opções de mercado ou investimentos que poderiam ser alterna- tivas ao uso da técnica do creep-feeding: a) rentabilidade zero - ponto em que o retorno proporcionado pelo ganho adicional do bezerro serviria apenas para cobrir exatamente os custos de suplementação; b) $0,6 \%$ - representa a rentabilidade da aplicação do capital na caderneta de poupança; c) 1,2\% - rentabilidade bruta obtida em fundos de renda fixa; e d) $6 \%$ remuneração média obtida no confinamento de bovinos de corte em anos favoráveis. Como fruto da maior ingestão de ração suplementar pelos bezerros, o custo de suplementação mais elevado foi proporcionado pelo tratamento SAL5 (R\$ 14,92. animal ${ }^{-1}$ ).

Na prática, o diferencial obtido pelo lote que recebeu suplemento com $5 \%$ de sal comum em relação ao lote controle foi de 7,2 kg. animal ${ }^{-1}$ à desmama, o que resultou em rentabilidade mensal líquida negativa para esse tratamento $(-12,5 \%)$. Para que os animais do tratamento SAL5 proporcionassem lucro zero, o diferencial de peso deveria ser de pelo menos $10,8 \mathrm{~kg}$. animal ${ }^{-1}$ à desmama, ou seja, de 5,2\% (5,2 kg de bezerro a mais em cada $100 \mathrm{~kg}$ de bezerro desmamado), conforme cálculo apresentado na Tabela 4 .

Para alcançar rentabilidades de 0,$6 ; 1,2$; e $6 \%$, o tratamento SAL5 deveria ter proporcionado aumentos de peso de 11,0; 11,2; e 12,8 kg. animal ${ }^{-1}$, respectivamente. Em valores relativos, o diferencial de peso em cada $100 \mathrm{~kg}$ de bezerro desmamado deveria ser de 5,$3 ; 5,4$; e $6,1 \%$, para rentabilidades de 0,$6 ; 1,2$; e $6 \%$, respectivamente. Esse diferencial é tanto mais difícil de se obter à medida que se elevam os custos dos ingredientes do suplemento e/ou ocorre conversão alimentar ruim no período chuvoso, quando os bezerros substituem forragem pelo suplemento.

O tratamento que se mostrou mais interessante foi o SAL10, cuja lucratividade já começaria a aparecer em diferenciais de peso à desmama acima de 7,6 kg.animal ${ }^{-1}$, ou seja, 3,5\% do peso corporal. A obtenção de 9,0 kg.animal ${ }^{-1}$, ou seja, 4,2 kg a mais em cada $100 \mathrm{~kg}$ de bezerro desmamado no tratamento que recebeu suplemento contendo $10 \%$ de $\mathrm{NaCl}$, proporcionou a notável rentabilidade de $6 \%$ ao mês, cerca de dez vezes a da mais popular aplicação financeira do mercado - a caderneta de poupança. Para alcançar rentabilidades de 0,6 e $1,2 \%$, o tratamento SAL10 deveria ter proporcionado aumentos de 7,7 e 7,8 kg.animal ${ }^{-1}$, respectivamente. Em valores relativos, o diferencial de peso em cada $100 \mathrm{~kg}$ de bezerro desmamado deveria ser de 3,6 e 3,7\%, para rentabilidades de 0,6 e $1,2 \%$, respectivamente.

É importante notar ainda que a relação entre o 
Tabela 4 - Análise econômica do uso do creep-feeding, conforme os tratamentos testados

Table 4 - Economic analysis of creep-feeding system, according to the evaluated treatments

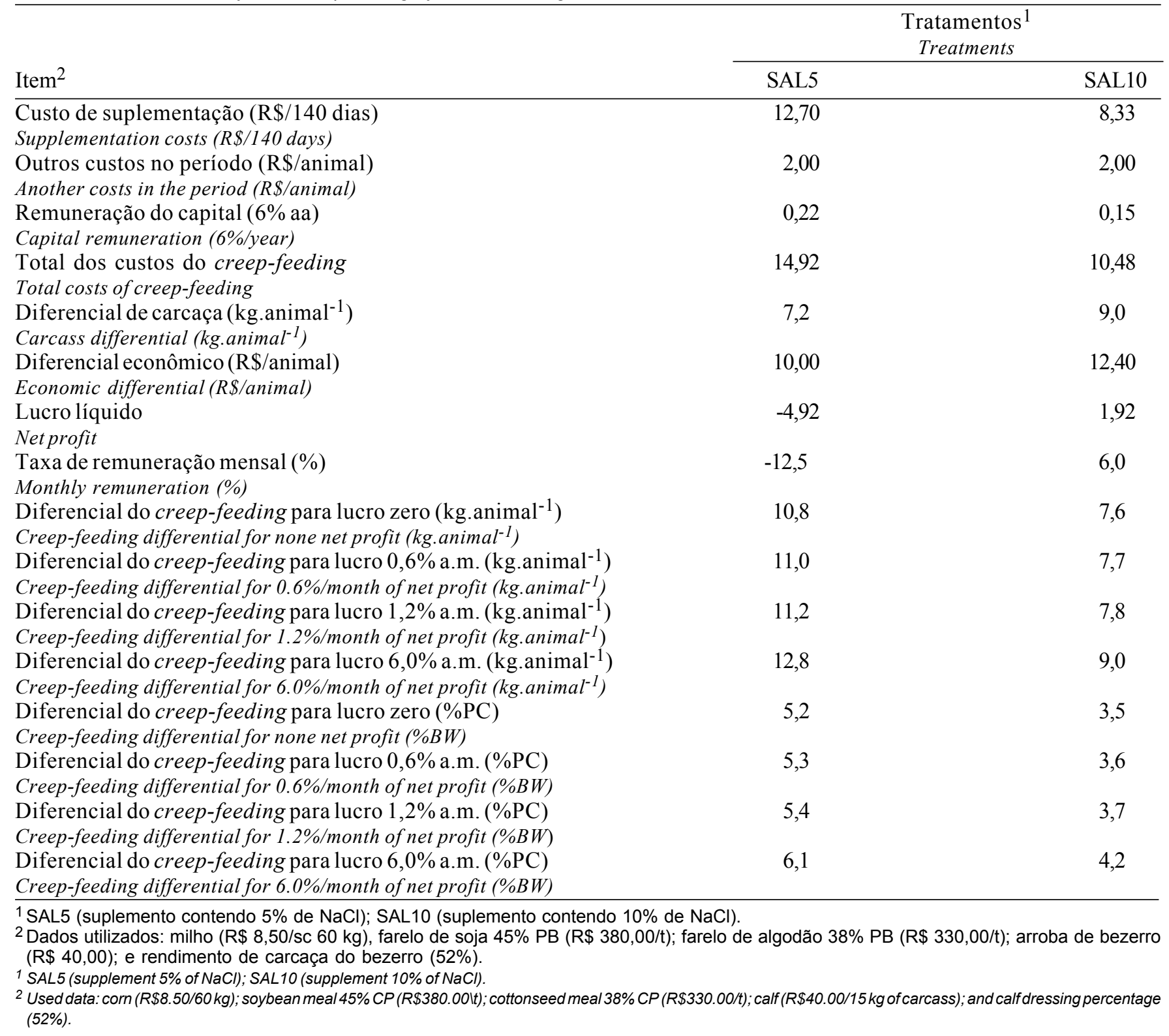

peso adicionado pela suplementação e o lucro obtido mostrou-se linear nos diversos tratamentos testados. Isso mostra que o creep-feeding proporciona, a partir de um peso diferencial mínimo específico para cada sistema produtivo (mínimo econômico), rentabilidade fixa para cada unidade de peso adicional que se obtém pela suplementação da dieta dos bezerros. Pelo presente estudo, há evidências de que a exploração do potencial genético do bezerro (máximo genético), desde que este situe-se acima do mínimo econômico, é regida por incrementos de ganho progressivos, que normalmente não tendem a se estabilizar. Embora pareça simples, a obtenção de diferen- cial de peso à desmama em bezerros que recebem suplemento no creep-feeding é dependente da interação de muitos fatores e, por vezes, pode ser algo suficientemente árduo, conforme exemplificado no presente estudo pelos tratamentos controle e SAL5. $\mathrm{O}$ criador deve estar sempre atento à eficiência de conversão no ganho de peso adicional. Em geral, aumentando-se o nível de nutrição do bezerro, prejudica-se a conversão do suplemento em peso adicional, pois se os bezerros estão ao pé de vacas boas de leite e pastejando forragem de boa qualidade, já deverão estar ganhando próximo, ou no mesmo nível, do seu potencial genético. Desta forma, o suplemento não 
aumentará as taxas de ganho, e os bezerros substituirão forragem, que deveriam ter ingerido, pelo suplemento. Caso isso aconteça e o ajuste da dieta seja inadequado, pode tornar-se praticamente impossível viabilizar o uso do creep-feeding, mesmo que seja necessário obter à desmama apenas $5,2 \%$ a mais em peso de bezerro, como mostrado pelo tratamento SAL5, no presente estudo.

\section{Conclusões}

A adição de $10 \%$ de $\mathrm{NaCl}$ ao concentrado fornecido no creep-feeding proporcionou maior ganho de peso corporal em relação aos animais que não receberam suplemento e tornou economicamente viável a adoção desta técnica de suplementação quando comparada à adição de $5 \%$ de $\mathrm{NaCl}$ ao concentrado.

\section{Literatura Citada}

AGRICULTURAL AND FOOD RESEARCH COUNCIL AFRC. Energy and protein requirements of ruminants. Wallingford: CAB International, 1993. 59p.

ASSOCIATION OF OFFICIAL ANALYTICAL CHEMISTS AOAC. Official methods of analysis. 16.ed. Washington, DC.: 1995. v.1, 30p.

BANZATTO, D.A.; KRONKA, S.N. Experimentação agrícola. 2.ed. Jaboticabal: Funep, 1992. 247p.

JARRIGE, R. Alimentación de bovinos, ovinos y caprinos. Madri: Mundi-Prensa, 1990. 431p.
LUSBY, K.S. Creep feeding beef calves. Oklahoma: Oklahoma Cooperative Service, 1995. 9p. (Circular 848)

MARTIN, T.G.; LEMENAGER, R.P.; SRINIVASAN, G. et al. Creep feeding as a factor influencing performance of cows and calves. Journal of Animal Science, v.53, n.1, p.33-39, 1981.

PACOLA, L.J.; NASCIMENTO, J.; MOREIRA, H.A. Alimentação suplementar de bezerros zebus: influência sobre a idade dos machos ao abate e das fêmeas à primeira cobrição. Boletim de Indústria Animal, v.34, n.2, p.177-201, 1977.

PACOLA, L.J.; RAZOOK, A.G.; BONILHA, NETO, L.M. et al. Suplementação de bezerros em cocho privativo. Boletim de Indústria Animal, v.46, n.2, p.167-75, 1989.

PACOLA, L.J.; RAZOOK, A.G.; BONILHA NETO, L.M. et al. Influência da suplementação em cocho privativo sobre o desempenho pós-desmama de bezerros Nelore. Boletim de Indústria Animal, v.48, n.1, p.13-18, 1991.

PACOLA, L.J.; RAZOOK, A.G.; FIGUEIREDO, L.A. et al. Suplementação pré e pós-desmama de fêmeas zebuínas da raça Nelore. Boletim de Indústria Animal, v.50, n.2, p.35-41, 1993.

TAYLOR, R.E.; FIELD, T.G. Beef production and management decisions. 3.ed. New Jersey: Prentice Hall, 1999. 714p. 